\title{
Early outcome of folding mitral valve repair technique without resection for mitral valve prolapse in 60 patients
}

\author{
Hiroyuki Tsukui, MD, PhD, Nobuhiro Umehara, MD, Hiroyuki Saito, MD, PhD, Satoshi Saito, MD, \\ $\mathrm{PhD}$, and Kenji Yamazaki, MD, PhD
}

\begin{abstract}
Objectives: Leaflet resection represents the reference standard for mitral valve regurgitation. However, the resection technique is irreversible and requires leaflet cutting and reapproximation. Folding mitral valve repair is a nonresectional technique with inversion of the prolapsed segment into the left ventricle. The present study evaluated the effectiveness of this technique.
\end{abstract}

\begin{abstract}
Methods: The prolapsed segment was inverted into the left ventricle vertically. A pilot suture was placed at the free edge of the leaflet. After confirming no mitral valve regurgitation with a pressure test, additional sutures were placed toward the annulus. If the test still showed mitral valve regurgitation, the suture was removed and repositioned. Ring annuloplasty was performed in all patients, except those with active infectious endocarditis. The repaired mitral valve was evaluated using echocardiography.
\end{abstract}

Results: A total of 60 patients ( 37 men; mean age, 62.4 years) underwent folding mitral valve repair from January 2007 to September 2011. Of these patients, 38 (63\%) had moderate and $18(30 \%)$ had severe mitral valve regurgitation preoperatively. Folding mitral valve repair was applied to the anterior leaflet and posterior leaflet. The mean cardiopulmonary bypass time and crossclamp time were 148 and 90 minutes, respectively. No patient had systolic anterior motion. Postoperative echocardiography revealed no mitral valve regurgitation to trivial mitral valve regurgitation in 48 and mild mitral valve regurgitation in 12 patients. No patient required reoperation for recurrent mitral valve regurgitation.

Conclusions: Folding mitral valve repair is an easily fine-tuned technique with a pilot suture, which can be easily removed and repositioned, if unsatisfactory. This reversibility is a significant advantage of this technique. Longterm follow-up is necessary to assess the durability of this technique. (J Thorac Cardiovasc Surg 2013;145:104-9)

Mitral valve repair has several advantages over mitral valve replacement, including lower operative mortality, improved left ventricular function, lower freedom from reoperation and complications related to anticoagulation, and superior long-term survival. ${ }^{1-3}$ The Society of Thoracic Surgeons database showed that the rate of mitral valve repair increased from $51 \%$ in 2000 to $69 \%$ in 2007 in the United States. ${ }^{4}$ Carpentier's technique ${ }^{5}$ for mitral valve repair, which incorporated both leaflet repair by quadrangular resection and annuloplasty, has been the most common technique for degenerative posterior leaflet disease. The principles of Carpentier's mitral valve repair include supporting the leaflet tissue, eliminating tension on the leaflet suture lines, and reinforcing the reconstruction with an

From the Department of Cardiovascular Surgery, Tokyo Women's Medical University, Tokyo, Japan.

Disclosures: Authors have nothing to disclose with regard to commercial support. Read at the 38th Annual Meeting of The Western Thoracic Surgical Association, Maui, Hawaii, June 27-30, 2012.

Received for publication June 24, 2012; revisions received Aug 1, 2012; accepted for publication Aug 23, 2012; available ahead of print Nov 5, 2012.

Address for reprints: Hiroyuki Tsukui, MD, PhD, Department of Cardiovascular Surgery, Tokyo Women's Medical University, 8-1 Kawada Shinjuku, 162-8666, Tokyo, Japan (E-mail: htsukui@wf7.so-net.ne.jp).

0022-5223/\$36.00

Copyright (c) 2013 by The American Association for Thoracic Surgery

http://dx.doi.org/10.1016/j.jtcvs.2012.08.063 annuloplasty ring. In patients requiring broad posterior leaflet resection, however, a very large defect needs to be covered by the thin, narrow remaining portion of the posterior leaflet, with aggressive annuloplasty, which can cause systolic anterior motion. The sliding technique represents a solution for systolic anterior motion ${ }^{6}$; however, this technique is irrevocable and requires precise leaflet cutting and suturing. The complexity of this procedure has been perceived to be difficult by surgeons. Gillinov and colleagues ${ }^{1}$ reported 64 of 3051 patients $(2.1 \%)$ had unsuccessful repair that was converted to replacement during the initial operation. Despite the several advantages of mitral valve repair, Bolling and colleagues ${ }^{7}$ reported the mean rate of mitral valve repair was $41 \%$ and the median number of mitral valve operations annually was 5 . Increased surgeon mitral volume was associated with an increased propensity to perform mitral valve repair. For example, for a surgeon performing 100 mitral cases annually, the risk-adjusted odds ratio for mitral valve repair was 3.78 times $(95 \%$ confidence interval, 1.87-7.64) that of a patient treated by a surgeon who performed the median number $(\mathrm{n}=5)$ of mitral cases annually. ${ }^{7}$

To overcome these problems, we used the folding mitral valve repair (FMVR) technique. This is a nonresectional technique with inversion of the prolapsed segment into the left ventricle and ring annuloplasty. 


\section{Abbreviations and Acronyms}

FMVR $=$ folding mitral valve repair

IE $=$ infectious endocarditis

MR = mitral valve regurgitation

\section{METHODS}

Mitral valve surgery was indicated for patients with mitral valve regurgitation (MR) greater than moderate or any MR with infectious endocarditis (IE). Between January 2007 and September 2011, 88 patients were eligible for mitral valve repair for mitral valve prolapse. Of the 88 patients with mitral valve prolapse, $60(68.2 \%)$ underwent mitral valve repair with the FMVR technique and 19 underwent the resection technique because of IE or surgeon preference. The remainder underwent repair with artificial chordae. After January 2009, the rate of FMVR increased, 53 of 60 patients with mitral valve prolapse $(88.3 \%)$ received the FMVR technique. The pre- and postoperative data were retrospectively analyzed.

\section{OPERATIVE TECHNIQUE}

All procedures were performed through a median sternotomy. The mitral valve was approached by way of a left atriotomy. A transseptal approach was applied to patients who required simultaneous tricuspid valve repair. Mitral ring annuloplasty sutures were placed and retracted to expose the mitral valve. The prolapsed segment of the mitral valve was identified with a saline pressure test (Figure 1, A). In patients with a prolapsed posterior leaflet, the prolapsed segment was inverted into the left ventricle vertically. A pilot suture of 5-0 monofilament polypropylene was placed vertically at the free edge of the prolapsed leaflet and tied temporarily with a single knot (Figure $1, B$ ). If the saline pressure test still showed MR, the suture was removed and repositioned. After confirming the absence of MR with the test, the pilot suture was tied securely, and additional interrupted sutures were placed toward the annulus (Figure 1,C). At this point, the mitral valve leaflet usually appeared to be competent with sufficient coaptation. In patients with a prolapsed commissural leaflet, the prolapsed segment and prolapsed posterior leaflet were inverted into the left ventricle. In patients with a prolapsed A1 or A3 segment, a pilot suture was placed on the edge of the prolapsed segment and brought out to the anterolateral or posteromedial annulus, respectively. In most cases, annuloplasty was added to the same segment to facilitate leaflet approximation with 3-0 monofilament polypropylene suture in a figure-of- 8 fashion. If the test still showed MR, artificial chordae were placed to adjust the leaflet height as needed. A full ring, Carpentier-Edwards Physio (Edwards Lifescience, LLC, Irvine, Calif) or Carpentier-Edwards Physio II (Edwards Lifescience, LLC), or a partial ring, CosgroveEdwards (Edwards Lifescience, LLC) was placed to prevent future annular dilation. The repaired mitral valve was evaluated using transesophageal echocardiography in the operating room and transthoracic echocardiography before discharge.

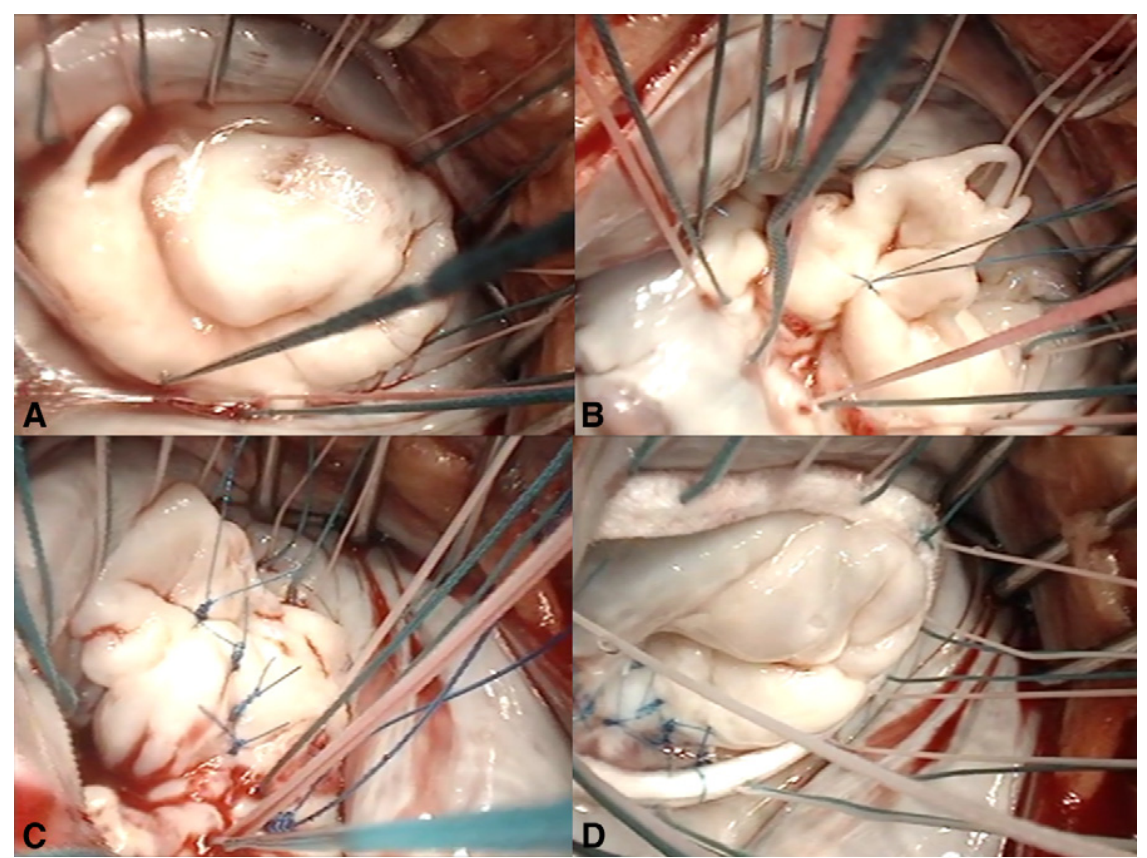

FIGURE 1. A, Saline pressure test showing large prolapsed P1 segment with torn chordae. B, P1 segment inverted vertically into left ventricle with 5-0 monofilament polypropylene pilot suture. Standard quadrangular resection technique would remove this segment. C, Annuloplasty with 3-0 monofilament polypropylene suture in figure-of- 8 fashion was added to same segment of prolapse, P1, to facilitate leaflet approximation and interrupted sutures were placed toward the annulus. D, Mitral valve was reconstructed with annuloplasty ring. Saline pressure test showed competent mitral valve with sufficient coaptation. 
TABLE 1. Patient demographics

\begin{tabular}{|c|c|}
\hline Variable & Value \\
\hline Patients (n) & 60 \\
\hline \multicolumn{2}{|l|}{ Age (y) } \\
\hline Mean \pm SD & $62.4 \pm 11.1$ \\
\hline Range & $37-84$ \\
\hline Male gender (n) & $37(61.7)$ \\
\hline \multicolumn{2}{|l|}{ Height $(\mathrm{cm})$} \\
\hline Mean \pm SD & $162.7 \pm 9.8$ \\
\hline Range & 144-189 \\
\hline \multicolumn{2}{|l|}{ Weight $(\mathrm{kg})$} \\
\hline Mean \pm SD & $57.4 \pm 11.4$ \\
\hline Range & $35-84$ \\
\hline \multicolumn{2}{|c|}{ Preoperative mitral valve regurgitation grade $(\mathrm{n})$} \\
\hline Moderate & $38(63.3)$ \\
\hline Severe & $18(30)$ \\
\hline Infectious endocarditis & 7 (11.7); healed, 6 \\
\hline \multicolumn{2}{|l|}{ Ejection fraction (\%) } \\
\hline Mean \pm SD & $55.7 \pm 7.0$ \\
\hline Range & $33-69$ \\
\hline \multicolumn{2}{|c|}{ Systolic pulmonary artery pressure $(\mathrm{mm} \mathrm{Hg})$} \\
\hline Mean \pm SD & $34.2 \pm 11.7$ \\
\hline Range & $17-70$ \\
\hline \multicolumn{2}{|l|}{ Left ventricular diameter at systole $(\mathrm{mm})$} \\
\hline Mean \pm SD & $36.3 \pm 7.6$ \\
\hline Range & $22-58$ \\
\hline \multicolumn{2}{|l|}{ NYHA functional class } \\
\hline I & $22(36.7)$ \\
\hline II & $35(58.3)$ \\
\hline III & $2(3.3)$ \\
\hline IV & $1(1.7)$ \\
\hline Preoperative cardiogenic shock & $2(3.3)$ \\
\hline Hypertension & $34(56.7)$ \\
\hline Hyperlipidemia & $21(35.0)$ \\
\hline Diabetes & $5(8.3)$ \\
\hline Smoking & $6(10)$ \\
\hline \multicolumn{2}{|l|}{ Creatinine level (mg/dL) } \\
\hline Mean \pm SD & $1.0 \pm 1.0$ \\
\hline Range & $0.5-8.6$ \\
\hline \multicolumn{2}{|l|}{ Total bilirubin level (mg/dL) } \\
\hline Mean \pm SD & $0.8 \pm 0.4$ \\
\hline Range & $0.3-1.8$ \\
\hline Hemodialysis & $1(1.7)$ \\
\hline Chronic obstructive pulmonary disease & $4(6.7)$ \\
\hline Cerebrovascular disease & $1(1.7)$ \\
\hline Previous cardiac surgery & $2(3.3)$ \\
\hline Urgent & $2(3.3)$ \\
\hline
\end{tabular}

\section{RESULTS}

A total of 60 patients with mitral valve prolapse underwent mitral valve repair with the FMVR technique. Preoperative echocardiography showed moderate MR in 38 $(63.3 \%)$ and severe MR in $18(30 \%)$; 7 patients $(11.7 \%)$ had IE preoperatively. However, 6 had been treated with antibiotics and the IE of 1 was not well controlled before surgery. Two patients $(3.3 \%)$ underwent urgent surgery
TABLE 1. Continued

\begin{tabular}{lc}
\hline \multicolumn{1}{c}{ Variable } & Value \\
\hline Prosthesis type and size & \\
Carpentier-Edwards Physio & 4 \\
$28 \mathrm{~mm}$ & 11 \\
$30 \mathrm{~mm}$ & 4 \\
$32 \mathrm{~mm}$ & \\
Carpentier-Edwards Physio II & 2 \\
$26 \mathrm{~mm}$ & 21 \\
$28 \mathrm{~mm}$ & 12 \\
$30 \mathrm{~mm}$ & 4 \\
$32 \mathrm{~mm}$ & \\
Cosgrove & 1 \\
30 mm & 1 \\
No prosthesis & $66(79.5)$ \\
Postoperative mitral valve regurgitation grade & $17(20.5)$ \\
None to trivial & 0 \\
Mild & 0 \\
Moderate & \\
Severe & \\
\hline Data in parentheses are percentages. NYHA, New York Heart & Association; SD, \\
standard deviation. & \\
& \\
&
\end{tabular}

because of cardiogenic shock. The perioperative data are summarized in Table 1.

In most patients, the mitral valve was approached by way of a left atriotomy. Of the 60 patients, $44(73 \%)$ had prolapse of a single segment, 33 of whom had posterior leaflet prolapse (P1, 3; P2, 12; P3, 18), and 16 (27\%) had prolapse of multiple segments, including 5 with both anterior and posterior leaflet prolapse. FMVR was applied to a single segment in 54 patients $(90 \%)$. Most FMVR was applied to the posterior leaflet (P1, 3; P2, 14; P3, 19). Simultaneous with FMVR, 51 patients $(85 \%)$ underwent annuloplasty to the same lesion in which FMVR was applied. Two patients $(3.3 \%)$ required multiple annuloplasties, placing more than 2 annuloplasty stitches to reduce the annular size, for the posterior leaflet $(\mathrm{P} 2+\mathrm{P} 3,1$ and $\mathrm{P} 1+\mathrm{P} 2+\mathrm{P} 3,1)$. The mitral valve pathologic data and FMVR data are summarized in Tables 2 through 4 . Of the 60 patients, 59 (98.3\%) received a full or partial ring, including CarpentierEdwards Physio in 19 (31.7\%), Carpentier-Edwards Physio II in $39(65 \%)$, and Cosgrove ring in $1(1.7 \%)$. Ring selection was surgeon preference. One patient received no ring because of active IE. This patient had vegetation at the tip of both prolapsed leaflets. FMVR was applied after the vegetation had been completely removed. No ring was placed to prevent recurrence of infection. Five patients $(8.3 \%)$ had artificial chordae placed (A1 in 1, A2 in 1, A3 in 2, and $\mathrm{P} 2$ in 1). Concomitant procedures included correction of arrhythmia in $23(38.3 \%)$, tricuspid valve repair in 14 $(23.3 \%)$, coronary artery bypass grafting in $5(8.3 \%)$, and aortic valve replacement in $3(5 \%)$. The cardiopulmonary bypass and aortic crossclamp time was $147.7 \pm 37.1 \mathrm{~min}-$ utes and $89.8 \pm 27.1$ minutes, respectively. Intraoperative 
TABLE 2. Prolapsed segment

\begin{tabular}{lc}
\hline Segment & Patients (n) \\
\hline Single $(\mathrm{n}=44)$ & \\
A1 & $4(6.7)$ \\
A2 & $0(0)$ \\
A3 & $5(8.3)$ \\
AC & $1(1.7)$ \\
P1 & $3(5)$ \\
P2 & $12(20)$ \\
P3 & $18(30)$ \\
PC & $1(1.7)$ \\
Multiple (n 16$)$ & \\
A1, AC & $1(1.7)$ \\
A1, P1 & $1(1.7)$ \\
A1, P3 & $1(1.7)$ \\
A2, A3 & $2(3.3)$ \\
A2, A3, AC & $1(1.7)$ \\
A2, A3, P3 & $1(1.7)$ \\
A3, P3 & $2(3.3)$ \\
A3, PC & $3(5)$ \\
P1, P2 & $1(1.7)$ \\
P1, P2, P3 & $1(1.7)$ \\
P2, P3 & $1(1.7)$ \\
P3, PC & $1(1.7)$ \\
\hline D &
\end{tabular}

Data in parentheses are percentages. $A C$, Anterolateral commissure; $P C$, posteromedial commissure.

transesophageal echocardiography showed that no patient had systolic anterior motion after bypass. Postoperative transthoracic echocardiography revealed no MR to trivial MR in $48(80 \%)$ and mild MR in $12(20 \%)$ before discharge. All patients were discharged and were still alive at the last follow-up visit. Follow-up transthoracic echocardiography was performed in 35 patients $(58.3 \%)$ after discharge (mean postoperative period, 518 days; range, 80-1763) and showed no MR to trivial MR in 18 and mild MR in 17. No patient required reoperation for recurrent MR.

\section{DISCUSSION}

Several simplified mitral valve repair techniques without leaflet resection have been reported. Calafiore and colleagues ${ }^{8}$ plicated the posterior leaflet horizontally to the annulus by passing "U" sutures from the annulus to the midportion of the scallop to reduce the height of the prolapsing myxomatous scallops. Tabata and colleagues ${ }^{9}$ and Mihaljevic and colleagues ${ }^{10}$ also described horizontal folding valvuloplasty without leaflet resection for myxomatous posterior mitral valve disease. They placed sutures from the leaflet free edge to the annulus on the prolapsed or redundant portion of the posterior leaflet, causing the midscallop to fold under itself. Woo and MacArthur ${ }^{11}$ modified the McGoon plication repair. ${ }^{12}$ The prolapsed posterior leaflet was inverted vertically into the left ventricle with a double-running CV5 polytetrafluoroethylene suture
TABLE 3. Folding segment

\begin{tabular}{lc}
\hline Segment & Patients (n) \\
\hline Single $(\mathrm{n}=54)$ & \\
A1 & $6(10)$ \\
A2 & $0(0)$ \\
A3 & $7(11.7)$ \\
AC & $1(1.7)$ \\
P1 & $3(5)$ \\
P2 & $14(23.3)$ \\
P3 & $19(31.7)$ \\
PC & $4(6.6)$ \\
Multiple (n =6) & \\
A1, P1 & $1(1.7)$ \\
A2, A3 & $1(1.7)$ \\
A2, A3, P3 & $1(1.7)$ \\
A3, PC & $1(1.7)$ \\
P2, P3 & $1(1.7)$ \\
P3, PC & $1(1.7)$ \\
\hline
\end{tabular}

Data in parentheses are percentages. $A C$, Anterolateral commissure; $P C$, posteromedial commissure.

(Gore-Tex; WL Gore \& Associates Inc, Flagstaff, Ariz). These techniques were used for prolapsed posterior leaflet only.

Our technique, FMVR, is an easily fine-tuned technique with a pilot suture, which can be easily removed and repositioned, if unsatisfactory. This reversibility is a significant advantage and might contribute to a greater repair rate. We have no case that was converted to replacement during the initial operation in the present study.

In the setting of the leaflet resection technique, putting sutures on the remaining thin leaflet can result in leaflet tearing and subsequent MR. FMVR might be able to lower this risk, because the sutures are placed on the thickened leaflet owing to degeneration with wider suture bites. After successful FMVR experience with the posterior leaflet, we have expanded the indications for FMVR to the anterior and commissural leaflets. In cases with a prolapsed

TABLE 4. Annuloplasty segment

\begin{tabular}{lc}
\hline Segment & Patients (n) \\
\hline Single $(\mathrm{n}=51)$ & \\
A1 & $3(5)$ \\
A2 & $0(0)$ \\
A3 & $1(1.7)$ \\
AC & $3(5)$ \\
P1 & $3(5)$ \\
P2 & $13(21.7)$ \\
P3 & $23(38.3)$ \\
PC & $5(8.3)$ \\
Multiple (n =2) & \\
P1, P2, P3 & $1(1.7)$ \\
P2, P3 & $1(1.7)$ \\
No annuloplasty & $7(11.7)$ \\
\hline Data in parentheses are percentages. $A C$, Anterolateral commissure; $P C$, posterome- \\
dial commissure.
\end{tabular}


commissural leaflet, MR was controlled by inverting the prolapsed leaflet into the left ventricle and annuloplasty and repair of the prolapsed posterior leaflet. In cases with a prolapsed A1 or A3 segment, 1 arm of the suture was placed on the free edge of the prolapsed leaflet, and the other arm was brought out to the anterolateral or posteromedial annulus to invert a part of the prolapsed anterior segment. Annuloplasty was not always applied to the anterior leaflet. As needed, artificial chordae were added to adjust the leaflet height.

The simplicity and reproducibility of this technique make it a potentially attractive alternative for minimally invasive, endoscopic, and robotic mitral valve procedures. Also, the reversibility of this technique provides a chance for residents to gain experience in mitral valve repair.

A potential risk of infection or thromboembolism exists, related to the inverted tissue. We have had no infection or thromboembolism to date. Anticoagulation with warfarin (Coumadin sodium) was continued for 2 months only after surgery unless the patient had an indication for long-term anticoagulation.

The limitations of this repair include that it might be difficult to apply this technique to calcified leaflets. It might not be possible to apply this technique to the $\mathrm{A} 2$ segment, and artificial chordae will still be required for some cases with a prolapsed anterior leaflet. The present study was retrospective, and the duration of follow-up was short ( $<5$ years). A larger patient series and long-term follow-up are necessary to assess the efficacy and durability of this technique.

\section{CONCLUSIONS}

FMVR is an easy technique without resection for repair of the prolapsed mitral valve. The propalsed segment was inverted into the left ventricle vertically with a pilot suture, which can be easily removed and repositioned, if unsatisfactory. This reversibility is a significant advantage of this technique. Good short-term outcomes were observed. This technique can also be applied to anterior leaflet pathologic entities in selected patients.

\section{References}

1. Gillinov AM, Blackstone EH, Nowicki ER, Slisatkorn W, Al-Dossari G, Johnston DR, et al. Valve repair versus valve replacement for degenerative mitral valve disease. J Thorac Cardiovasc Surg. 2008;135:885-93.

2. Moss RR, Humphries KH, Gao M, Thompson CR, Abel JG, Fradet G, et al. Outcome of mitral valve repair or replacement: a comparison by propensity score analysis. Circulation. 2003;108(Suppl II):90-7.

3. Jokinen JJ, Hippeläinen MJ, Pitkänen OA, Hartikainen JEK. Mitral valve replacement versus repair: propensity-adjusted survival and quality-of-life analysis. Ann Thorac Surg. 2007;84:451-8.

4. Gammie JS, Sheng S, Griffith BP, Peterson ED, Rankin JS, O'Brien SM, et al. Trends in mitral valve surgery in the United States: results from the Society of Thoracic Surgeons Adult Cardiac Surgery Database. Ann Thorac Surg. 2009; 87:1431-7.

5. Carpentier A. Cardiac valve surgery-the "French correction." J Thorac Cardiovasc Surg. 1983;86:323-37.

6. Carpentier A. The sliding leaflet technique. Le Club Mitrale Newsletter. 1988; $1: 5$.
7. Bolling SF, Li S, O’Brien SM, Brennan JM, Prager RL, Gammie JS. Predictors of mitral valve repair: clinical and surgeon factors. Ann Thorac Surg. 2010;90: 1904-11.

8. Calafiore AM, Di Mauro M, Actis-Dato G, Iacò AL, Centofanti P, Forsennati P, et al. Longitudinal plication of the posterior leaflet in myxomatous disease of the mitral valve. Ann Thorac Surg. 2006;81:1909-10.

9. Tabata M, Ghanta RK, Shekar PS, Cohn LH. Early and midterm outcomes of folding valvuloplasty without leaflet resection for myxomatous mitral valve disease. Ann Thorac Surg. 2008;86:1388-90.

10. Mihaljevic T, Blackstone EH, Lytle BW. Folding valvuloplasty without leaflet resection: simplified method for mitral valve repair. Ann Thorac Surg. 2006;82: e46-8.

11. Woo WJ, MacArthur JW Jr. Simplified nonresectional leaflet remodeling mitral valve repair for degenerative mitral regurgitation. J Thorac Cardiovasc Surg. 2012;143:749-53.

12. McGoon DC. Repair of mitral insufficiency due to ruptured chordae tendineae. J Thorac Cardiovasc Surg. 1985;89:491-8.

\section{Discussion}

Dr D. Craig Miller (Stanford, Calif). Dr Tsukui, welcome to Hawaii and the Western Thoracic Surgical. Very nice presentation, paper, and video.

I have 2 comments and 2 questions. Number 1 is a comment. This was an elegant presentation, but we must remember that what you are calling "foldoplasty" is not new. It is actually a very old technique, analogous to what Dwight McGoon pioneered 50 years ago at the Mayo Clinic. What you are showing is very similar, but why are we trying to reincarnate these ancient McGoon techniques today? The McGoon "V-excision" repair had been abandoned everywhere, except at the Mayo Clinic, until the last decade when it was resurrected by Tommy Mihaljevic, the New York University group, and Larry Cohen. More recently, Joe Woo at Pennsylvania published a repair technique very similar to yours in the Journal of Thoracic and Cardiovascular Surgery, which I call the "dunkoplasty," where you just bury the excess posterior scallop prolapse down inside the ventricle. The question remains-why are some groups reincarnating these old techniques? I will get to this in a minute.

A couple questions now. What is your patient follow-up magnitude and extent? You have been doing this for about 5 years, but I did not see any follow-up mentioned in the paper. I did not see any 1-year or 2-year echocardiographic results, nor did I see any 1-year or 2-year echocardiographic results. How can we judge if your approach has merit if we do not know the follow-up and at least the short-term echocardiographic results?

Dr Tsukui. Thank you very much for your questions. As you pointed out, this is a type of McGoon technique, which was already performed before. Our concept is a little bit different from that of Dr Cohen's or Dr Woo's, because our stitch is really easy to remove after being placed. In addition, Dr Cohen's technique is a horizontal technique, but our technique is vertical. The reason we started this technique for mitral valve regurgitation is it is easier to teach the residents. Once a resident cuts the mitral valve inappropriately, we cannot fix it, but if we use this technique, we can repair the valve again after removing the pilot stitch. That is why we started this technique.

As you pointed out, we do not have long-term outcomes yet. The oldest one is just 4 years. Now we are examining echocardiographic data for mitral valve at our outpatient clinic, and we did not have significant mitral regurgitation (MR), as I showed here. Also, we are checking the B-type natriuretic peptide level, which 
showed improvement of heart failure. I could not show the B-type natriuretic peptide level data today, but I would like to show you at the next WTSA [Western Thoracic Surgical Association] annual meeting.

Dr Miller. Okay, that is interesting, because it leads to my next question. Because most of your patients were asymptomatic or minimally symptomatic, New York Heart Association class I or II preoperatively, is having $20 \%$ of patients have residual mild MR at hospital discharge acceptable quality? I do not believe that result will help us convince cardiologists that early repair for asymptomatic patients is justified. You can almost get that good a repair with an Abbott MitraClip or 2, at about \$US20,000 a pop. Is that really satisfactory surgical quality?

Dr Tsukui. This is my personal impression, but cardiologists' evaluations are really tough for cardiac surgeons. They diagnose even really small regurgitation as "mild" MR after surgery. I am not sure, but if we do not have any progression of MR for a couple of years after surgery, we could tell this technique is effective. We will see in the next couple years.

Dr Miller. Good. That is what I was asking for-late echocardiographic results. I am surprised the B-type natriuretic peptide levels were elevated preoperatively, because most of your patients really did not have many symptoms. Perhaps you could put those data in your paper when Dr Cohen gives you the chance to revise it.

This leads me to my chief comment, which is something we all should do some soul searching about. Why are we striving to bring back these older, simpler techniques? Was not the McGoon "V-excision" judged long ago to be obsolete, except at the Mayo Clinic? Only recently, coupled with the advent of robotic mitral surgery, has it resurfaced and is now in vogue in Cleveland and Ranny Chitwood's center in East Greenville, North Carolina? These old methods had been jettisoned over the years and replaced by newer resectional methods, "slidingplasty," and the Gore-Tex neochord techniques at most experienced mitral centers. Has the resurgence of interest in "folding plasty" and/or simple McGoon "V-excision" just been due to the stampede to perform surgery through a smaller hole or with robotic assistance? Why should we compromise our surgical approach and our surgical outcome standards just to do something more quickly using minimal invasively approaches? This worries me. Additionally, to make the repair simpler (or "dumb it down") so that it can be applied just to raise the $69 \%$ national rate of repair to $90 \%$ by more surgeons, who do not see a lot of mitral valve cases-recall that the average number of mitral repair or replacement operations performed is only 5 per US surgeon annually-could backfire and come back to haunt us if the results are not as good as that reported from the high-volume centers. I tell David Adams every time I see him he is being unrealistic when he tells all of us that we must repair at least $95 \%$ of regurgitant mitral valves. Marc Gillinov has shown clearly that a good mitral replacement is much better than a suboptimal repair. We simply cannot afford to compromise our surgical repair outcomes. The cardiologists are lurking to jump on this and will claim your repair results are no better than those with a MitraClip. We must remember that our surgical goal, especially in patients with asymptomatic or minimally symptomatic prolapse, is to have a nearly perfect repair and show our cardiologists satisfactory echocardiographic results 10 or more years later. If we do not achieve that goal, we are not giving our patients the best solution to their problem. I am already concerned that the results of mitral valve repair are deteriorating nationwide in the United States; yes, more repairs are being done, but the results might not be as good as earlier reported from high-volume mitral institutions. If this is true, the cardiologists are going to see this as an opportunity to do something with an intervention because our standards have slipped to a point at which they might be able to equal them.

In summary, we look forward to you coming back in a few years with the 5-year echocardiographic results that will demonstrate whether this simplified technique has merit. Congratulations on a nice presentation. Thank you.

Dr Tsukui. Thank you.

Dr Scott McClure (Boston, Mass). Nice presentation. As Dr Miller just alluded, at the Brigham, Dr Cohn will often use and teach a "folding plasty" repair, in which he folds the posterior leaflet back from the free edge to the annulus. For years, Dr Sari Aranki at the Brigham has used a repair technique that seems quite similar to what you have described today, in which he invaginates a portion of the posterior leaflet downward into the left ventricular cavity. When deciding whether to use their "folding plasty" repairs, Drs Cohn and Aranki generally differentiate between those patients who have myxomatous disease with elongated chords and those with myxomatous disease and ruptured chords. Barring the odd exception to the rule, they would tend to perform a leaflet resection if they identified any major ruptured chords within the prolapsing segment of the leaflet. My question is this: I just want to know whether a similar distinction is made at your center before performing a "folding plasty" or whether you use this technique in the presence of both elongated and rupture chords indiscriminately?

Dr Tsukui. Thank you for the question. For the ruptured chordae case, we applied the "folding plasty" technique first. Sometimes, as you pointed out, we still have prolapse owing to the ruptured chordae. At that time, we place artificial chordae to pull the prolapsed leaflet down to the left ventricle or, as you pointed out, we cut it out, if it is really large. 